\title{
State-of-the-Art Intersection Support in Coal Mines in the USA
}

\author{
A.J.S. Spearing Southern Illinois University Carbondale, USA
}

A. Mueller Southern Illinois University Carbondale, USA

\begin{abstract}
The support of intersections, particularly in coal mines, remains an important issue in the USA and the most common area for unplanned falls of ground. In recent years, considerable progress has been made in reducing rock related accidents in coal mines and it remains an on-going research area. This paper reviews the current state-of-the-art and suggests areas that could be improved.
\end{abstract}

\section{Introduction to US coal mining}

In 2006, the US produced a record of 1,057 million metric tonnes (1.163 million short tonnes) of coal. Coal is actively mined in 33 States in the USA and about $90 \%$ of the production is used to generate power, approximately $50 \%$ of the country's electricity needs. This production comes from 1,438 mines of which 612 are underground mines. Production from underground mines accounts for about $31 \%$ of the total coal produced. The State of Wyoming in the north-west is the largest producer, mainly due to a huge surface coal field in the Powder River Basin, the largest coal deposit in the world that traverses Montana and Wyoming. In 2006, a single surface operation produced over 80 million $t$ of coal from the Basin. This is followed by West Virginia (Appalachia) and Kentucky (Interior and Appalachia) that have considerable tonnages from underground mines. Figure 1 shows the major coal regions in the USA and the 2006 tonnage with the change from the 2005 tonnage in brackets.

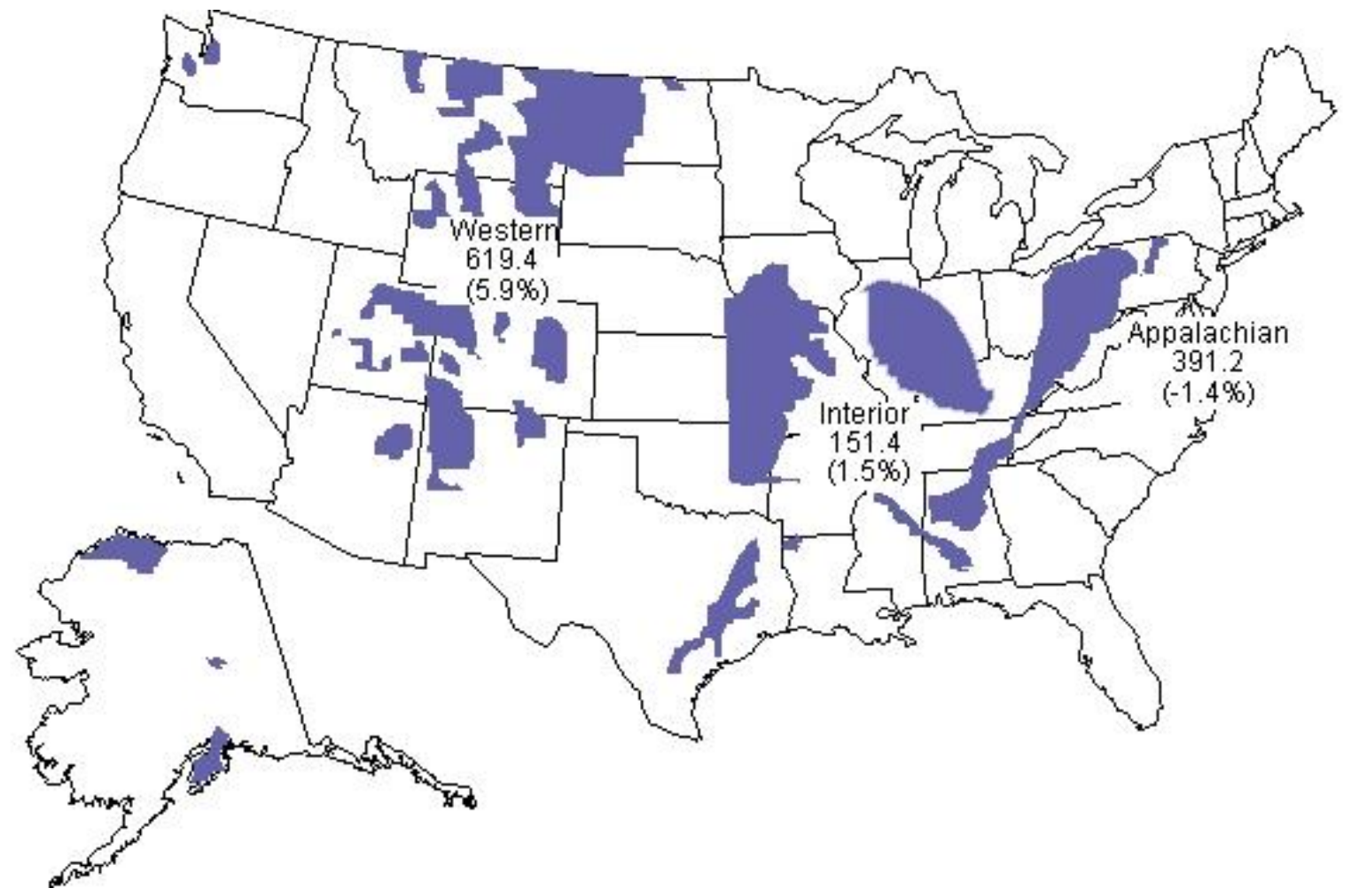

Figure 1 Coal production by region in millions of short tonnes - Energy Information Agency 
Coal mining produces over US\$60 billion in annual revenues and directly and indirectly supports over 750,000 jobs in the USA (Lilly, 2006).

In the public eye, coal is however not favourably received due to the hype about greenhouse gases, and some considerable misinformation. It is unfortunate that the proposed state-of-the art thermal power station (FutureGen) which was planned for Mattoon in Illinois has been cancelled due in the authors' opinions to politics and not science. This power station would have been as "clean" (near zero emissions) as current technology permits and would have utilised carbon dioxide sequestration. It was planned to be a joint venture between several international players and the US government was to have provided about $\$ 1.1$ billion of the estimated $\$ 1.8$ billion required funding through the Department of Energy. The joint venture partners include most of the significant coal mining companies (Peabody, Xstrata, BHP, Consol Energy, Foundation Coal, Rio Tinto and Anglo American) and energy producers, including a significant Chinese company (China Huaneng Group).

\section{Coal mine safety}

\subsection{A historical overview}

Safety had been improving steadily in underground mines. In 2005, the number of fatalities was the lowest ever at 23 , although clearly the goal must be zero fatalities. Table 1 shows the overall downward trend until 2005.

Table 1 Historical fatality data for US coal mines (Energy Information Administration)

\begin{tabular}{cccccccc}
\hline Year & $\begin{array}{c}\text { Number } \\
\text { of Miners }\end{array}$ & $\begin{array}{c}\text { Production } \\
\text { (Metric tonnes } \\
\left.10^{6}\right)\end{array}$ & Fatalities & Year & $\begin{array}{c}\text { Number of } \\
\text { Miners }\end{array}$ & $\begin{array}{c}\text { Production } \\
\text { (Metric tonnes x } \\
\left.10^{6}\right)\end{array}$ & Fatalities \\
\hline 1911 & 666,552 & \pm 418 & 2821 & 1996 & 126,451 & 967 & 39 \\
1984 & 208,160 & 814 & 125 & 1997 & 126,429 & 991 & 30 \\
1985 & 197,049 & 803 & 68 & 1998 & 122,083 & 1016 & 29 \\
1986 & 185,167 & 809 & 89 & 1999 & 114,489 & 1000 & 35 \\
1987 & 172,780 & 835 & 63 & 2000 & 108,098 & 976 & 38 \\
1988 & 166,278 & 864 & 53 & 2001 & 114,458 & 1025 & 42 \\
1989 & 164,929 & 892 & 68 & 2002 & 110,966 & 995 & 28 \\
1990 & 168,625 & 936 & 66 & 2003 & 104,824 & 974 & 30 \\
1991 & 158,677 & 905 & 61 & 2004 & 108,734 & 1011 & 28 \\
1992 & 153,128 & 907 & 55 & 2005 & 116,436 & 1029 & 23 \\
1993 & 141,183 & 859 & 47 & 2006 & 122,975 & 1056 & 47 \\
1994 & 143,645 & 940 & 45 & 2007 & N/A & 1043 & 33 \\
1995 & 132,111 & 939 & 47 & 2008 & N/A & & 15 to date \\
\hline & & & & & & $(06 / 16)$ \\
\hline
\end{tabular}


It should be noted that 1911 was the year when the most fatalities occurred and 2005 the year when the least fatalities occurred to date.

In 2006, the coal mining industry was plagued by two major disasters; in January 2006 an explosion at the Sago Mine in West Virginia killed 12 people, followed in May 2006 by five miners being killed in another explosion at the Darby Mine in Kentucky. In August 2007, a further disaster occurred at the Crandall Canyon Mine in Utah from a massive collapse possibly caused by a coal bump that resulted in nine miners being killed and a further three more during rescue operations.

\subsection{Mining law}

The US Congress passed the Federal Mine Safety and Health Act of 1977 (Mine Act), and this amended the 1969 Coal Act in several significant ways. It also consolidated all the federal health and safety regulations of the mining industry under a single statutory scheme. It strengthened and expanded the rights of miners, and enhanced the protection of miners from retaliation for exercising those rights (such as the right to refuse to work in dangerous conditions). The Mine Act also transferred responsibility for enforcement from the Department of the Interior to the Department of Labor, and renamed the new agency the Mine Safety and Health Administration (MSHA). Under this Mining Act, safety continued to improve steadily.

Following the three recent mining disasters, Congress rapidly passed the Mine Improvement and New Emergency Response (MINER) Act in 2006. The Act deals mainly with three areas. They are Prevention, Escape, and Rescue and Response. The main provisions of this Act according to MSHA are:

- Require each mine to develop and continuously update a written emergency preparedness plan, which must be re-certified by MSHA every six months.

- Use equipment and technology that is commercially available if it can improve safety.

- Require every mine to have two experienced rescue teams capable of responding within one hour if required.

- Require mine operators to report dangerous incidents and accidents within 15 minutes to MSHA or face fines of up to US\$60,000.

- Raising the criminal penalty cap to $\$ 250,000$ for the first offence and a maximum civil penalty of $\$ 220,000$ for flagrant violations.

- Direct that within three years, mines will have wireless two-way communication and electronic tracking systems in place.

- Empower MSHA to shut down a mine when it has refused to pay a final order penalty.

- Install underground mine refuge chambers.

- The installation of directional lifelines and tethers in main escape-ways.

- Additional caches of Self-Contained Self-Rescuers.

According to the National Mining Association (NMA), a lobbying group representing many mine producers, the mines have reacted positively to this and more than 150,000 new Self Contained Self Rescuers (SCSR) have been introduced; all main escape-ways have lifelines; additional SCSR caches have been provided, almost 1000 refuge facilities have been commissioned or are on order (providing 96 hours of air); 45 new rescue teams have or are being trained and redundant communication systems have been installed.

Whilst these provisions have little directly to do with accidents associated with falls of ground, these still remain a cause of concern with mine operators and MSHA. The magnitude of the problem is given in Tables 2 and 3. It can clearly be seen that more progress is needed to reduce these fatalities and injuries from falls of ground. 
Table 2 Fall of ground fatalities in underground US coal mines

\begin{tabular}{lcccccc}
\hline Type of Fall & 2002 & 2003 & 2004 & 2005 & 2006 & 2007 \\
\hline Roof fall & 4 & 2 & 3 & 9 & 7 & 3 \\
Rib fall & 0 & 1 & 1 & 0 & 3 & 9 \\
Machinery related roof fall & 0 & 0 & 0 & 0 & 0 & 0 \\
\hline
\end{tabular}

Table 3 Fall of ground injuries in underground US coal mines

\begin{tabular}{lcccccc}
\hline Type of Fall & 2002 & 2003 & 2004 & 2005 & 2006 & 2007 \\
\hline Roof fall & 249 & 211 & 216 & 457 & 430 \\
Rib fall & 65 & 49 & 61 & 90 & 100 \\
Machinery related roof fall & 297 & 257 & 270 & 7 & 2 \\
\hline
\end{tabular}

One of the provisions of the MINER Act, however, that does impact on rock related safety is that all unplanned roof falls must be reported to a central MSHA office by telephone within 15 minutes of it being discovered. MSHA defines an unplanned roof fall as one that is at or above the anchorage zone in active workings where roof bolts are in use; or, an unplanned roof or rib fall in active workings that impairs ventilation or impedes passage. This information is then relayed to the relevant MSHA District Office where a decision is made as to whether an investigation is justified and whether the area should be barricaded (dangered) off to keep all personnel clear.

On the coal mines, MSHA is divided into 11 Districts all with a central District Office in order to be in close proximity to the local coal mining areas. Most Districts also have local offices as each mine must also be thoroughly inspected four times per annum by MSHA, aside from other visits.

\section{Intersection support}

Support in US coal mines is generally classified as either primary support, secondary support or supplemental support. Primary and secondary support are specified in each mines' Roof Control Plan. Primary support is generally rock bolts or anchors that are installed in the development cycle. Secondary support typically consists of cable bolts, trusses and/or standing support. Supplemental support is support installed over and above the primary and secondary support when conditions are worse than those designed for, due to weathering for example or for rehabilitation of an excavation.

The estimated breakdown of rock anchor usage in the US mining industry as a whole (Tadolini and Mazzoni, 2006 ) is about $68 \%$ passive resin rebar, $9 \%$ resin-assisted bolts, $12 \%$ tensioned rebar, $4 \%$ friction bolts (hard rock mines only), $4 \%$ mechanically anchored bolts and the balance mainly cable bolts and trusses. There is an on-going trend for the mines to use more resin grouted bolts, due to their advantages. This can be clearly seen because in an earlier 1988 study, only $40 \%$ of the rock anchors were passive resin rebar.

Intersections are of particular concern regarding roof stability because the span across the diagonal is large, typically $40 \%$ more than the room width. The diagonal span can be effectively even larger if the pillar corners are rounded during their development, incorrectly edged during development or if the pillar corners are damaged due to stress. Approximately $71 \%$ of all roof falls occur in intersections even though they only account for 20 to $25 \%$ of the total development, so a fall is 8 to 10 times more likely to occur in an intersection than an entry on a unit length basis. Numerical modelling and statistical analysis has shown that although four-way intersections are 1.28 times as likely to fail as three-way intersection, it takes two 3-way intersections to replace a single 4-way intersection. This makes the potential remedy of replacing 3-ways with 4-ways ineffective at reducing the total number of roof falls in these areas (Molinda et al., 1998). 


\subsection{Factors affecting intersection stability}

The stress $\left(\sigma_{\mathrm{xx}}\right)$ on the roof increases in proportion to the square of the span. Beam theory shows that maximum normal stress is given by:

$$
\sigma_{x x(\max )}=\frac{\gamma L^{2}}{2 t}
$$

Maximum deflection $\left(\eta_{\max }\right)$ at the centre of a beam is affected even more by an increase in the span:

$$
\eta_{\max }=\frac{\gamma L^{4}}{32 E t^{2}}
$$

Where $\gamma$ is the unit weight, $\mathrm{L}$ is the beam/room span and $\mathrm{t}$ is the beam thickness.

The in situ properties that have the greatest effect on intersection stability can be characterised using the Coal Mine Roof Rating (CMRR) Method. These parameters combined with the magnitude and orientation relative to the entry of the maximum horizontal stress $\left(\sigma_{\mathrm{hmax}}\right)$ can provide an empirical basis for anticipating stability problems. The CMRR, developed by the Bureau of Mines in 1994, evaluates defects, discontinuities, and strength of the immediate roof strata. The rock sample is assigned a number between 0 and 100 that can be used in engineering calculations to help in pillar design, intersection sizing, and other applications. The simplest way to evaluate CMRR is to use the software by the same name developed by NIOSH. Typically roofs with CMRR $<25$ tend to fail very soon after mining, so the working range is $25-100$ (Mark et al., 2001). Case studies confirm that a higher CMRR is related to lower number of roof falls, even a difference of 10 can affect roof stability significantly. One mine in West Virginia had a weak shale $(C M R R=40)$ and a rock fall rate that was 3.4 times more than a nearby mine with a stronger shale (CMRR=50) - (Mark et al., 2001).

Other factors that also have an influence on the intersection stability include the bolt length, stiffness, spacing, strength, orientation and installation quality as well as the timing of the support installation after the entry is developed.

The goal of any support system is to achieve the equilibrium of the rock mass around the excavation. A concept called the ground reaction curve has been used in the tunnelling industry for many years (Brown et al., 1983) and can be utilised to estimate how much support is needed to achieve roof equilibrium. These curves plot the support pressure against the convergence, as shown in Figure 2.

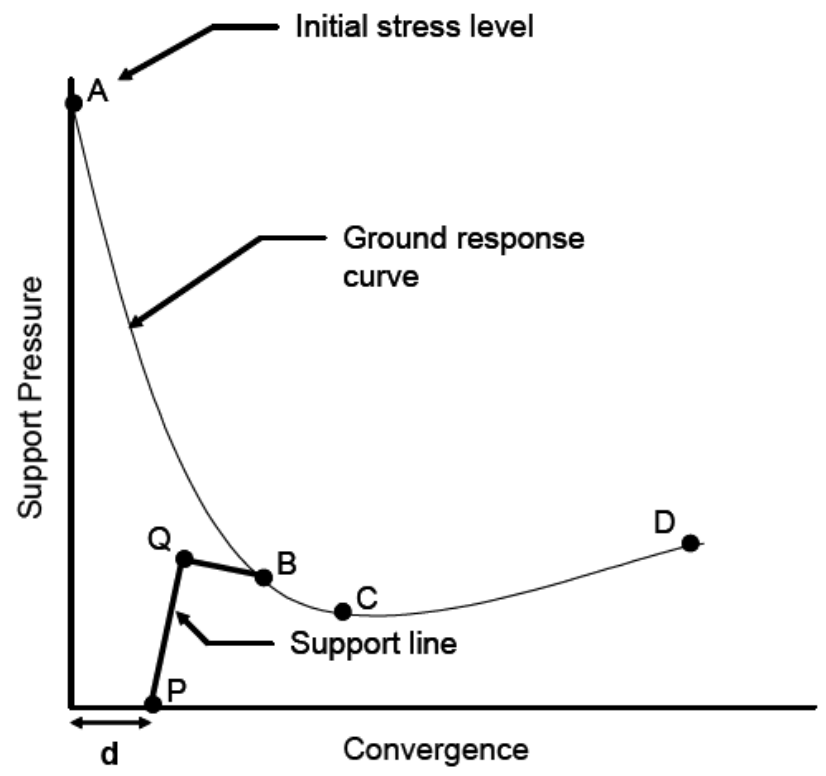

Figure 2 Illustration of a ground reaction curve (Barczak, 2006) 
Before excavation, the boundaries have stress equal to the in situ field stress (Point A in Figure 2). Once the excavation is developed, the reactive/support stress that is required to prevent additional convergence reduces as the rock structure begins self-supporting (Point B). A point is reached where serious rock failure and unravelling occurs (Point $\mathrm{C}$ ), and the self-supporting capacity reduces significantly; the rock deformation/deterioration accelerates and the required reactive load to create stability increases significantly. Ultimately (near Point D), the installed support needs to carry deadweight (i.e. all the failed ground). Equilibrium for the example shown is at Point B, where the support curve intersects the ground reaction curve. Using numerical modelling and in situ measurements of closure, these ground reaction curves and support interactions can be established to find the optimal method of support for a particular roof geology and location (Speers and Spearing, 1996; Barczak, 2006).

\subsection{Current intersection support practices}

All underground coal mines must submit a Roof Control Plan to the relevant MSHA District Office for approval. This includes the minimum support to be installed under the prevailing ground control conditions at the mine. It must be regularly updated as conditions dictate or if any support is to be changed.

A snap-shot survey of the intersection supports used on coal mines by the authors reveals the following:

- The heights of the numerous different coal seams mined tend to vary from 1.1 to $2.5 \mathrm{~m}$ in the east to 1.8 to $3.5 \mathrm{~m}$ in the west. Entry widths (rooms) are typically from 5.5 to $6.2 \mathrm{~m}$.

- Primary rock bolt support spacing (on cycle) is commonly $1.2 \mathrm{~m}$.

- Primary bolts vary from 1.1 to $2.5 \mathrm{~m}$ in length.

- Cable bolts are commonly installed as secondary support in intersections, with lengths typically between 2.5 and $4.9 \mathrm{~m}$. These tend to be installed in insufficient numbers to support any substantial dead weight.

- The vast majority of the supports are installed vertically.

- The bolts closest to the ribs are typically installed between 0.6 and $1.2 \mathrm{~m}$ from the ribs.

\subsubsection{The steel used for rock bolts}

A relatively wide variety of steel members are used as rock bolts as detailed in Table 4 below.

Table 4 Commonly used steel for rock bolting and the hole diameters used

\begin{tabular}{|c|c|c|c|}
\hline $\begin{array}{c}\text { Steel Material } \\
\text { (Diameter and Grade) }\end{array}$ & $\begin{array}{c}\text { Minimum Yield } \\
\text { Stress } \\
(\mathrm{MPa}) \\
\end{array}$ & $\begin{array}{l}\text { Recommended Anchor } \\
\text { Hole } \\
\text { Diameter }(\mathrm{mm})\end{array}$ & $\begin{array}{l}\text { Annulus } \\
(\mathrm{mm})\end{array}$ \\
\hline 16 mm (\#5) Gr 60 & 414 & 25.4 & 4.7 \\
\hline 19 mm (\#6) Gr 40 & 276 & 25.4 & 3.2 \\
\hline 19 mm (\#6) Gr 60 & 414 & 25.4 & 3.2 \\
\hline 19 mm (\#6) Gr 75 & 517 & 25.4 & 3.2 \\
\hline 22 mm (\#7) Gr 40 & 276 & 28.6 to 34.9 & 3.3 to 6.5 \\
\hline $22 \mathrm{~mm}(\# 7)$ Gr 60 & 414 & 28.6 to 34.9 & 3.3 to 6.5 \\
\hline $22 \mathrm{~mm}(\# 7) \mathrm{Gr} 75$ & 517 & 28.6 to 34.9 & 3.3 to 6.5 \\
\hline
\end{tabular}




\subsubsection{The steel used for cable bolts}

The steel used in cable bolts is given in Table 5 below.

Table 5 Cable properties and recommended hole diameters

\begin{tabular}{cccc}
\hline Steel Material & $\begin{array}{c}\text { Minimum Yield } \\
\text { Stress } \\
\text { (Diameter and Grade) }\end{array}$ & $\begin{array}{c}\text { Recommended Anchor } \\
\text { Hole }\end{array}$ & $\begin{array}{c}\text { Theoretical Annulus } \\
\text { Diameter }(\mathrm{mm})\end{array}$ \\
\hline $15 \mathrm{~mm}$ Gr 270 & 1862 & 25.4 to 34.9 & 5.2 to 10.0 \\
$18 \mathrm{~mm}$ Gr 270 & 1862 & 25.4 to 34.9 & 3.7 to 8.5 \\
\hline
\end{tabular}

The figures for the annulus when using cables are misleading because depending on the hole diameter used, the ends of the cables would be bulbed in various places and to specific diameters to ensure good resin mixing and adhesion to the cable.

The cables come in three forms; an untreated or black cable, a galvanised cable or an epoxy coated cable depending if corrosion is an issue. Typically only $1.2 \mathrm{~m}$ of the cable is resin grouted (point anchored) irrespective of the cable length mainly because of the insertion pressure when forcing the cables through more resin causes potentially serious installation problems.

\section{Unplanned falls of ground in intersections}

\subsection{Results}

An analysis of unplanned falls of ground has revealed interesting results. An example from one MSHA District Office is given in the following Figures. These are fairly representative from most of the Districts, particularly in the Interior and Appalachian Regions where the bulk of the underground mining occurs. It was also selected because the data was considered more accurate because all the falls detailed had been investigated by both the mines and the relevant MSHA District Roof Control Section. The dates were from 2006 to May 2008 and involved about 10 different underground mines.

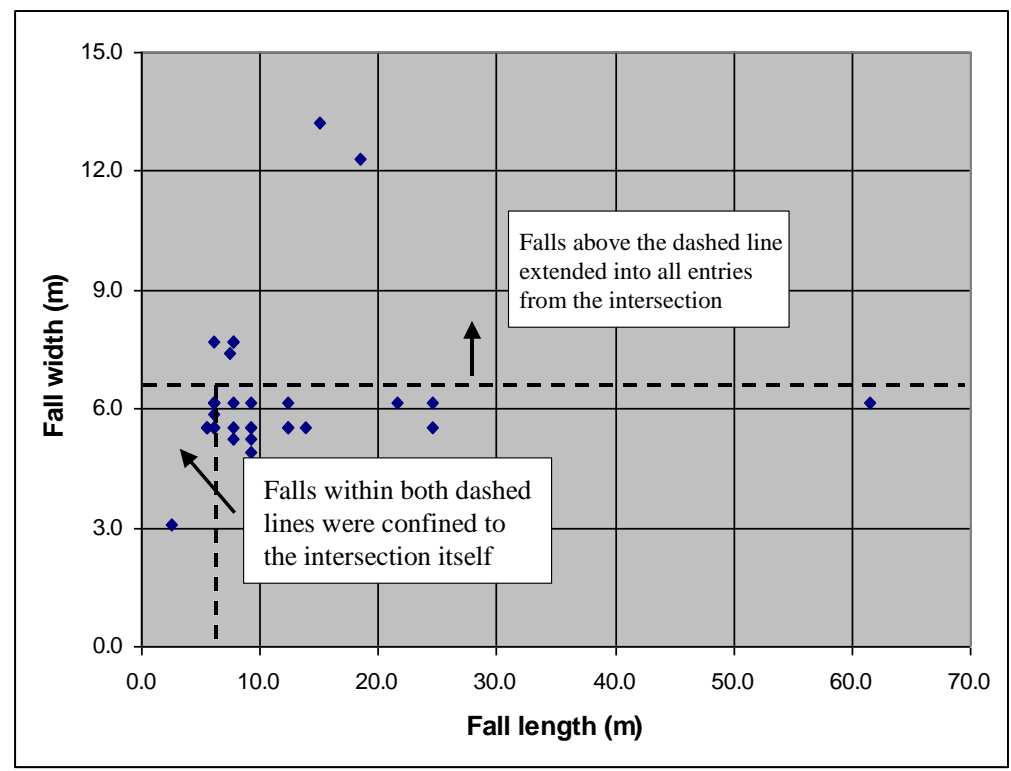

Figure 3 Unplanned fall of ground length versus width 
Figure 3 shows that there is no relationship between the fall length and the fall width and that most of the falls propagated well beyond the intersection itself at least in one direction. It is also interesting to note that the majority of the falls extended over the entire entry (room).

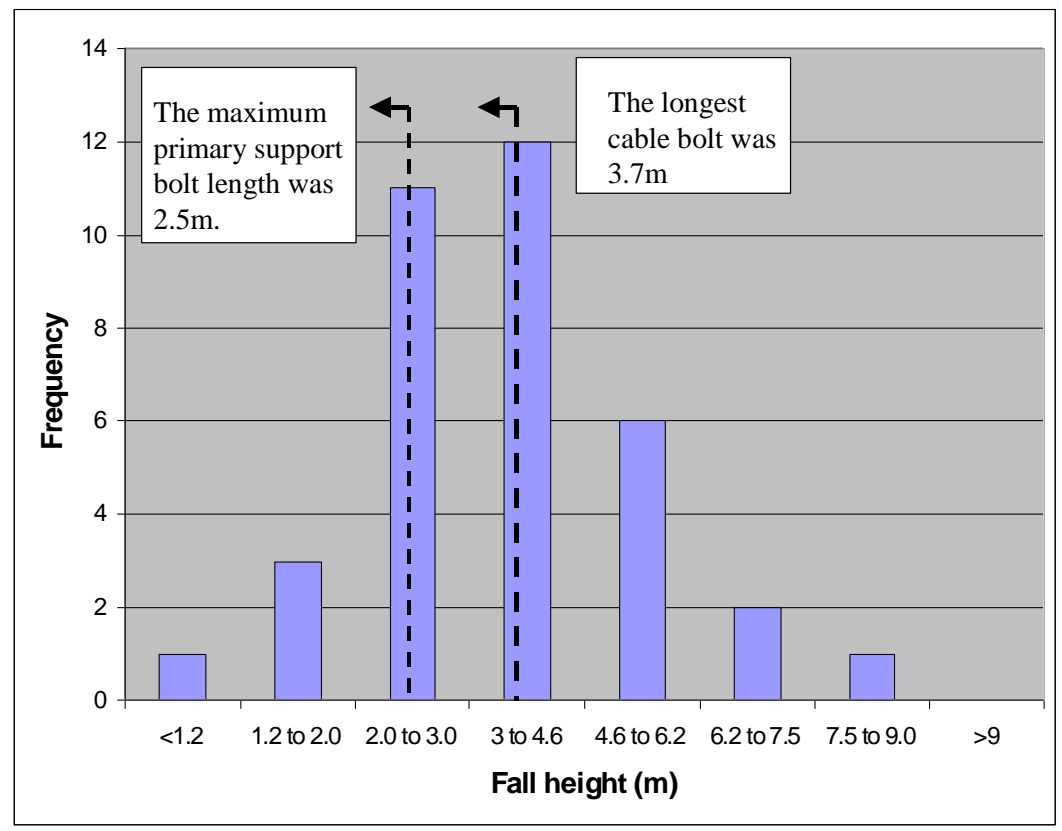

\section{Figure 4 Unplanned fall of ground heights}

Figure 4, which is from the same dataset, shows that there is basically no relationship between the fall height and the rock anchor length (remembering that to be defined by MSHA as an unplanned fall in this case it must be above the primary bolt anchorage). It is also significant that over half of the falls are above the longest cables installed too, although the number installed as secondary support in the intersections is such that they cannot carry the deadweight below their anchorage point (and are not designed to do this).

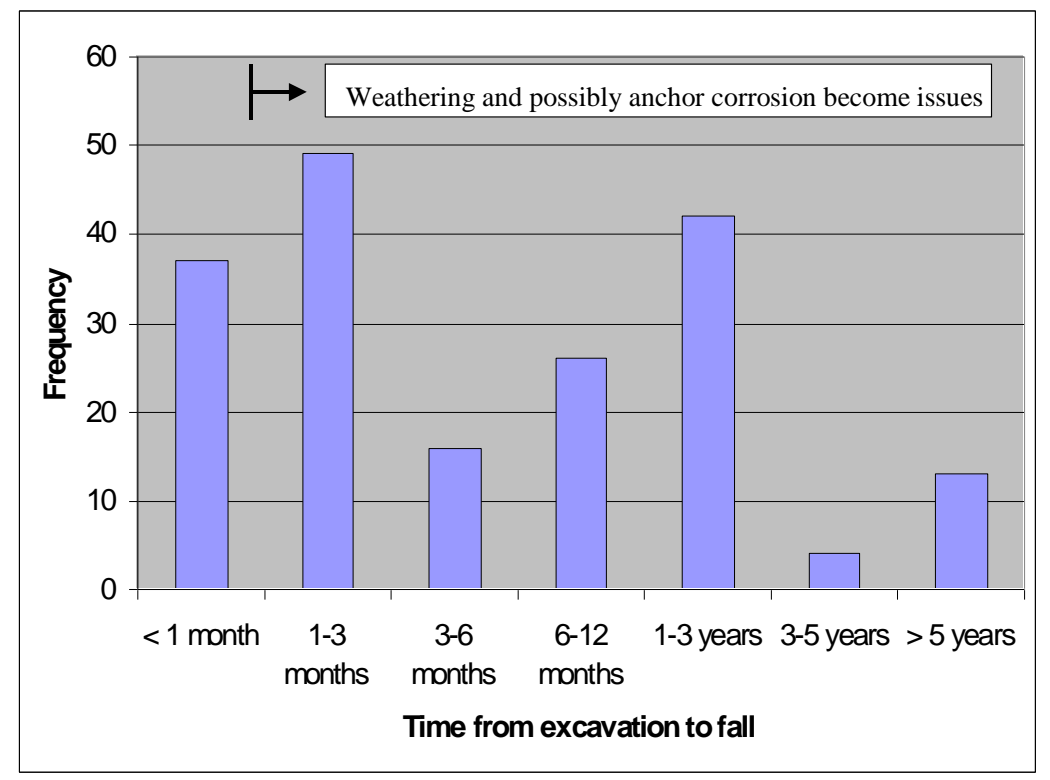

\section{Figure 5 Stand-up times}


Figure 5 gives the stand-up times for the unplanned falls and it is important to note that most occur well after the initial development and would tend to suggest that weathering and possibly corrosion become significant factors.

\subsection{Discussion}

It would appear from the data that reducing the potentially hazardous unplanned intersection falls of ground cannot readily be resolved by installing more and longer rock bolts vertically in and around the intersections. It would seem probable that the falls are caused by the cohesive failure of the "roof beam" around the perimeter of the intersection and along the pillars (over the room span). This is further supported because unplanned falls are defined as being above the anchorage point and basically all these falls were over the entire span (room). If this assessment is correct then the early onset of cutters along the pillar edges, as shown in Figure 6 may be indicative of such a potential future problem.

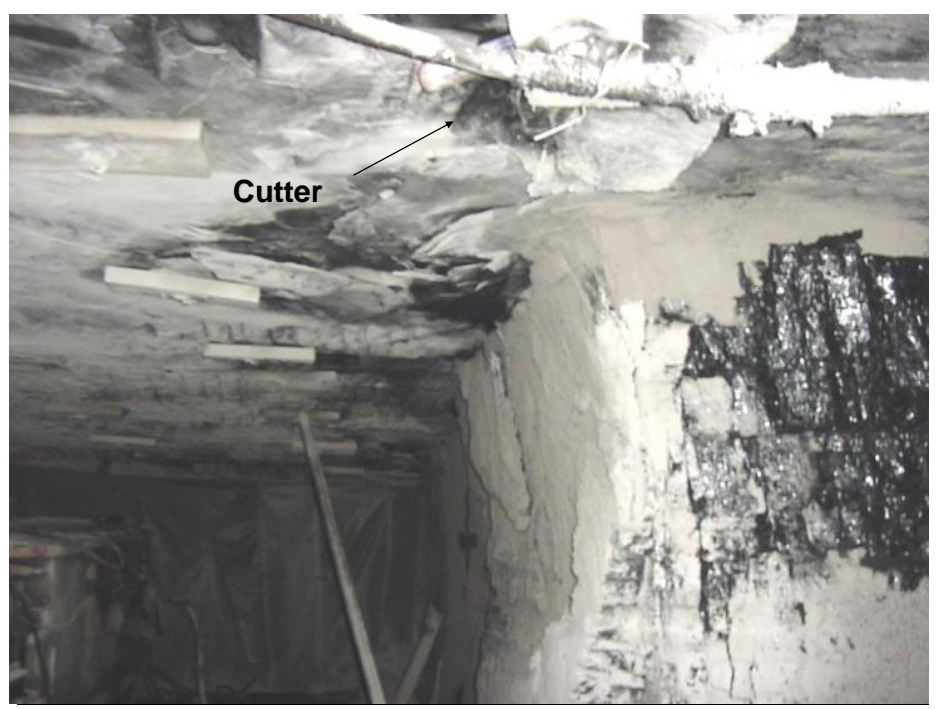

Figure 6 The onset of a cutter into the roof against the pillar rib

Although this clearly needs more investigation, should these cutters be pre-cursors of the collapses then after their formation, the only solution would seem to be the installation of free standing supports relatively close to the pillars.

Modern roof bolters are equipped with large mobile canopies to protect the operators but many of these tend to mean that rock bolts cannot be installed closer than about $0.6 \mathrm{~m}$ from the pillars. This could be a disadvantage since most of the unplanned falls are over the entire intersection area. Installing bolts closer to the pillars and angled over the pillars (as opposed to being vertical) would seem advantageous.

Weathering is also an important factor causing the falls and measures to counter this need to be considered. The common practice of installing screen/mesh does not really mitigate the effects of weathering.

\section{Recommendations}

Based on the data presented in this paper and the other related data it would seem that the following recommendations are appropriate:

- Just lengthening the primary bolts would not seem a solution to unplanned falls of ground in intersections.

- Methods to combat weathering (such as using sealants) need to be cost effectively developed for use in longer term key excavations.

- The actual cause of the falls needs to be established, is it cohesive failure in the roof along the pillar "knife edges" up to a weak roof parting? 
- The effect of corrosion of rock bolts under US coal mine conditions needs to be researched and quantified.

- The effectiveness of bolts installed closer to the pillars and possibly angled over the pillars should be tested.

\section{References}

Barczak, T. (2006) A retrospective assessment of longwall roof support with a focus on challenging accepted roof support concepts and design premises. Proceedings 25th International Conference on Ground Control in Mining, pp. 232-244.

Brown, E., Bray, J., Ladanyi, B. and Hoek, E. (1983) Ground response curves for rock tunnels. J. Geotech. Eng. 109, pp. 15-39.

Energy Information Administration. Annual Coal report for 2006 - DOE/EIA-0584(2006), pp. 6.

Lilly, P. (2006) Keynote Address. Proceedings 25th International Conference on Ground Control in Mining, pp. 1-7.

Mark, C., Molinda, G. and Dolinar, D. (2001) Analysis of Roof Bolt Systems. Proceedings 20th International Conference on Ground Control in Mining, pp. 218-225.

Molinda, G., Mark, C., Bauer, E.R., Babich, D.R. and Pappas, D.M. (1998) Factors Influencing Intersection Stability in U.S. Coal Mines. Proceedings 17th International Conference on Ground Control in Mining, pp. 267-275.

Speers, C. and Spearing, A. (1996) A methodology for the design of tunnel support in deep hard rock mines under quasi-static conditions. J. S. Afr. Inst. Min. Metall., Vol. 96, No. 2, pp. 47-54.

Tadolini, S. and Mazzoni, R. (2006) Understanding roof bolt selection and design still remains priceless. 25th International Conference on Ground Control, pp. 382-389. 